\title{
Note from the editors: Eurosurveillance special issue on leishmaniasis painting a picture of the situation in Europe
}

Eurosurveillance editorial team (eurosurveillance@ecdc.europa.eu) ${ }^{1}$

1. European Centre for Disease Prevention and Control (ECDC), Stockholm, Sweden

Citation style for this article:

Eurosurveillance editorial team. Note from the editors: Eurosurveillance special issue on leishmaniasis painting a picture of the situation in Europe. Euro Surveill. 2013;18(29): pii=20529. Available online: http://www.eurosurveillance.org/ViewArticle.aspx?Articleld=20529

Article published on 18 July 2013

After the publication of a special issue on Chagas disease in September 2011, this is the second time we focus on diseases caused by pathogens belonging to the family Trypanosomatidae. Even though Trypanosoma cruzi and Leishmania spp. infections have different impact on health, they are (still) neglected and we would like to raise awareness for aspects related to public health.

At the end of March 2012, we invited contributions for a special issue with the main aim to contribute to the existing body of evidence and to make available data that can help paint a better picture of the epidemiological situation and burden of autochthonous leishmaniasis in Europe [1]. The initial response was limited and we prolonged the deadline for submissions until the end of August 2012. The prolongation coincided with the allocation the first impact factor for Eurosurveillance [2] and, in addition to this, a leading European expert kindly supported the call and spread the word among his peers. We are not able to judge which element had most influence, however, by the end of the August deadline we had received 35 contributions from 16 countries for the special issue.

The evaluation of these manuscripts was a challenge for the editorial team and the supporting experts. We needed to apply stricter criteria and select only those papers which we deemed of highest interest for the readers of Eurosurveillance. This led to favouring papers focusing on human disease and in particular surveillance.

In the selection process we were forced to reject also manuscripts of good quality, and after peer review we agreed to publish 12 articles from 10 countries in Europe to ensure a good geographical representation. The coordination of the special issue took some time and we thank all contributors, peer reviewers and supporters, in particular Luigi Gradoni from the Istituto Superiore di Sanità in Rome, Italy, for their engagement and patience.
In this first part of the special issue we present surveillance data from five endemic countries in southern Europe: Bulgaria, Greece, Croatia, Italy and France, together with a rapid communication on an increase in leishmaniasis cases in northern Italy in 2012-13. The second part of the special issue will be published on 25 July. It will feature an editorial by Luigi Gradoni and two papers from Spain on a recent outbreak in Madrid with some unusual findings. Data from the Netherlands, a non-endemic country where a series of cases imported from within Europe were detected, will also be presented. Moreover, it will cover various relevant topics such as the role of indigenous phlebotomine sandflies and mammals in spreading the pathogen as well as aspects related to treatment with tumour necrosis factor-alpha antagonists and new diagnostic methods.

References

1. Call for papers for a special issue on the epidemiology of leishmaniasis in Europe . Euro Surveill. 2012;17(12):pii=20126. Available from: http://www.eurosurveillance.org/ViewArticle. aspx?Articleld $=20126$

2. Steffens I. Our first impact factor. Euro Surveill. 2012;17(27): pii=20214. Available from: http://www. eurosurveillance.org/ViewArticle.aspx?Articleld=20214 